\title{
Differential expression and regulation of Tdo2 during mouse decidualization
}

\author{
Dang-Dang Li*, Ying-Jie Gao*, Xue-Chao Tian, Zhan-Qing Yang, Hang Cao, \\ Qiao-Ling Zhang, Bin Guo and Zhan-Peng Yue
}

College of Veterinary Medicine, Jilin University, Changchun 130062, People's Republic of China *(D-D Li and Y-J Gao contributed equally to this work)
Correspondence should be addressed to B Guo or Z-P Yue Emails guobin79@jlu.edu.cn or yuezp@jlu.edu.cn

\begin{abstract}
Tryptophan 2,3-dioxygenase ( $T d o 2$ ) is a rate-limiting enzyme which directs the conversion of tryptophan to kynurenine. The aim of this study was to examine the expression and regulation of Tdo2 in mouse uterus during decidualization. Tdo2 mRNA was mainly expressed in the decidua on days 6-8 of pregnancy. By real-time PCR, a high level of Tdo2 expression was observed in the uteri from days 6 to 8 of pregnancy, although Tdo2 expression was observed on days 1-8. Simultaneously, Tdo2 mRNA was also detected under in vivo and in vitro artificial decidualization. Estrogen, progesterone, and 8-bromoadenosine-cAMP could induce the expression of $T d o 2$ in the ovariectomized mouse uterus and uterine stromal cells. Tdo2 could regulate cell proliferation and stimulate the expression of decidual marker Dtprp in the uterine stromal cells and decidual cells. Overexpression of Tdo2 could upregulate the expression of $A h r, \operatorname{Cox} 2$, and Vegf genes in uterine stromal cells, while Tdo2 inhibitor 680C91 could downregulate the expression of Cox2 and Vegf genes in uterine decidual cells. These data indicate that Tdo2 may play an important role during mouse decidualization and be regulated by estrogen, progesterone, and CAMP.
\end{abstract}

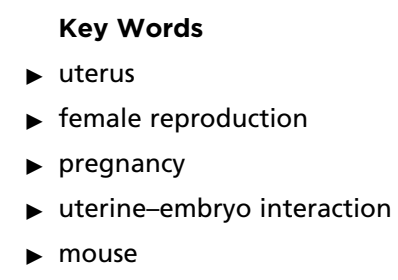

Journal of Endocrinology (2014) 220, 73-83

\section{Introduction}

Tryptophan is an essential amino acid that is required for the biosynthesis of proteins and also a precursor of neurotransmitter 5-hydroxytryptamine (serotonin) which has been identified within the CNS, vasculature, gastrointestinal tract, and female reproductive tract (Stone \& Darlington 2002, Doherty et al. 2011). In mammals, most of tryptophan was metabolized along the kynurenine pathway and tryptophan metabolism was closely correlated with pregnancy (Stone \& Darlington 2002, Schröcksnadel et al. 2006). During pregnancy, decreased tryptophan concentration and increased concentrations of kynurenines were observed in human plasma and in the uteri of mice and cows (Minatogawa et al. 2003,
Schröcksnadel et al. 2006, Groebner et al. 2011). Previous studies have found that tryptophan metabolism was mainly dependent on tryptophan 2,3-dioxygenase (Tdo2) and indoleamine 2,3-dioxygenase (Ido) (Stone \& Darlington 2002). Ido was expressed in dendritic cells, macrophages, giant trophoblasts in mice, and in extravillous trophoblast and villous trophoblast in humans, and could prevent rejection of the allogeneic fetus by suppressing the activation of maternal decidual T lymphocytes (Munn et al. 1998, Saito et al. 2007). During the gestation period, Ido was strongly expressed in the mouse concepti and placenta from days 8.5 to 12.5 of post-coitus (Suzuki et al. 2001, Minatogawa et al. 2003). Unexpectedly,

Published by Bioscientifica Ltd 
tryptophan-degrading activity was also observed on days 5.5-9.5 of post-coitus, and was not inhibited by the Ido inhibitor 1-methyltryptophan (Suzuki et al. 2001, Minatogawa et al. 2003). These results indicate that tryptophan metabolism in early gestation is due to Tdo2 activity.

Tdo2 is an initial and rate-limiting enzyme in the metabolism of tryptophan and might catalyze the oxidative cleavage of the indole ring of L-tryptophan to $\mathrm{N}$-formylkynurenine in the kynurenine pathway (Thackray et al. 2008). Tdo2-deficient mice displayed an elevation of plasma tryptophan, making more of this amino acid available for uptake into the brain, where it is converted to serotonin (Kanai et al. 2009). Tdo2 has also been identified in skin, brain, epididymis, testis, and early concepti, although it was mainly expressed in the liver (Suzuki et al. 2001, Minatogawa et al. 2003, Britan et al. 2006). Accumulating data have shown that Tdo2 was expressed in endometrial stromal cells and could be regulated by Hoxa10 gene, which was essential for decidualization (Benson et al. 1996, Germeyer et al. 2009, Doherty et al. 2011, Zhang et al. 2013). According to our (B Guo and X-C Tian unpublished observations) microarray data, Tdo2 was strongly expressed by day 8 decidua and deciduoma under artificial decidualization compared with the untreated uterine horn. However, the expression and regulation of Tdo2 in mouse uterus during decidualization have not been defined so far. Thus, this study was undertaken to examine the expression and regulation of Tdo2 in the mouse uterus during early pregnancy, by in situ hybridization and real-time PCR.

\section{Materials and methods}

\section{Animals}

Matured Kunming white strain mice ( $6-8$ weeks old) were caged in a controlled environment with a cycle of $14 \mathrm{~h}$ light:10 h darkness. All animal procedures were approved by the Institutional Animal Care and Use Committee of Jilin University. To confirm reproducibility of results, at least three mice per group were used in each stage or treatment in this study.

\section{Pregnancy and pseudopregnancy}

Adult female mice were mated with fertile or vasectomized males of the same strain to induce pregnancy or pseudopregnancy by cocaging respectively (day $1=$ day of vaginal plug). On days $1-4$, pregnancy was confirmed by recovering embryos from the oviducts or uterus.
The implantation sites on day 5 were identified by i.v. injection of $0.1 \mathrm{ml}$ of $1 \%$ Chicago blue (Sigma) in $0.85 \%$ sodium chloride.

\section{Artificial decidualization}

Artificial decidualization was induced by intraluminally infusing $25 \mu$ of sesame oil into one uterine horn on day 4 of pseudopregnancy, while the contralateral uninjected horn served as a control. The uteri were collected on day 8 of pseudopregnancy. Decidualization was confirmed by weighing the uterine horn and by histological examination of the uterine sections.

\section{Steroid hormonal treatments}

Mature female mice were ovariectomized and, after 2 weeks, given a single s.c. injection of estrogen (100 $\mathrm{ng} /$ mouse) or progesterone ( $2 \mathrm{mg} / \mathrm{mouse}$ ) (Guo et al. 2012). The uteri were then collected $1,3,6,12$, and $24 \mathrm{~h}$ after steroid treatment. To examine whether nuclear receptors for estrogen or progesterone are involved in steroid hormonal regulation, ovariectomized mice received injections of ICI 182780 (an estrogen receptor antagonist) or RU486 (a progesterone receptor antagonist) $1 \mathrm{~h}$ before estrogen or progesterone injection respectively. Each mouse received an injection of ICI 182780 and RU486 at a dose of $500 \mu \mathrm{g}$ and $1 \mathrm{mg}$ respectively (Guo et al. 2012). All steroids and antagonists were dissolved in sesame oil and injected subcutaneously. Controls received the vehicle only ( $0.1 \mathrm{ml} /$ mouse).

\section{In situ hybridization}

Total RNA from the mouse uteri was reverse-transcribed and amplified with Tdo2 primers. Tdo2 forward primer $5^{\prime}$-GGCATGGCTGGAAAGAACAC-3' and reverse primer 5'-CTCCCTGGAGTGCACGGTAT-3' were designed based on the sequence of the Mus musculus Tdo2 gene (GenBank accession number: NM_019911). The amplified fragment $(257 \mathrm{bp})$ of Tdo2 was cloned into pGEM-T plasmid (pGEM-T Vector System 1, Promega) and verified by sequencing. Tdo2-containing plasmid was amplified with the primers of T7 and SP6 to prepare templates for labeling (T7, 5'-TAATACGACTCACTATAGGG-3'; SP6, 5'-CATACGATTTAGgTGACACTATAG-3'). Digoxigenin (DIG)-labeled antisense and sense cRNA probes were transcribed in vitro using a DIG RNA labeling kit (Roche Diagnostics GmbH).

The frozen sections $(10 \mu \mathrm{m})$ were mounted on 3-aminopropyltriethoxy-silane (Sigma)-coated slides

Published by Bioscientifica Ltd 
and fixed in $4 \%$ paraformaldehyde solution in PBS. Hybridization was performed as described previously (Tian et al. 2013). The sections were counterstained with $1 \%$ methyl green in $0.12 \mathrm{M}$ glacial acetic acid. The sense probe was also hybridized and served as a negative control. There were no detectable signals from sense probes.

\section{Real-time PCR}

Total RNAs from mouse uteri or cultured cells were isolated using TRIPURE Reagent according to the manufacturer's instructions (Roche) and reverse-transcribed into cDNA using M-MLV reverse-transcriptase (Promega). The reverse transcriptase reaction was performed at $42^{\circ} \mathrm{C}$ for $60 \mathrm{~min}$ with $2 \mu \mathrm{g}$ total RNA in $25 \mu \mathrm{l}$ volume. For real-time PCR, cDNA was amplified using FS Universal SYBR Green Real Master (Roche) with a Bio-Rad CFX96 Real-Time Detection System. The conditions used for real-time PCR were as follows: $95^{\circ} \mathrm{C}$ for $3 \mathrm{~min}$, followed by 40 cycles of $95^{\circ} \mathrm{C}$ for $15 \mathrm{~s}$ and $60^{\circ} \mathrm{C}$ for $1 \mathrm{~min}$. All reactions were run in triplicate. The results were analyzed using CFX Manager Software (Foster City, California, USA). After analysis using the $2^{-\Delta \Delta C \mathrm{t}}$ method, data were normalized to Gapdh expression. Primer sequences for real-time PCR are listed in Table 1.

\section{Isolation of uterine stromal cells and in vitro decidualization}

Uterine stromal cells from day 4 of pregnancy were isolated and cultured, as described previously (Tian et al. 2013). Uterine stromal cells were induced for in vitro decidualization with a fresh medium supplemented with progesterone $(1 \mu \mathrm{M})$ and estrogen $(10 \mathrm{nM})$ in DMEM-F12 with $2 \%$ charcoal-treated FBS (Biological Industries Ltd., Kibbutz Beit Hemeek, Israel).

\section{Steroid hormonal treatments in vitro}

The cultured stromal cells were treated with $100 \mathrm{nM}$ of progesterone or $0.1 \mathrm{nM}$ of estrogen respectively. For further studies, cells were pretreated with RU486 $(1 \mu \mathrm{M})$ or ICI $182780(100 \mathrm{nM})$ antagonist for $2 \mathrm{~h}$ before the addition of progesterone or estrogen respectively. Then cells were collected at $24 \mathrm{~h}$ for further quantitative analysis using real-time PCR. All steroids and antagonists were dissolved in ethanol. Controls received the vehicle only.

\section{Isolation of uterine decidual cells}

Uteri were collected aseptically on day 7 of pregnancy and were trimmed of mesentery and fat, slit longitudinally, and the conceptuses were removed. The remaining tissues were washed three times with HBSS and further digested with $1 \mathrm{mg} / \mathrm{ml}$ collagenase I for $30 \mathrm{~min}$ at $37^{\circ} \mathrm{C}$ with shaking. The digested tissues were filtered and centrifuged at $200 \mathrm{~g}$. The cell pellets were washed twice with HBSS and resuspended in a complete medium consisting of DMEM-F12 with $10 \%$ heat-inactivated FBS. The viable cells were counted by trypan blue staining using a hemocytometer. The cells were plated onto $35-\mathrm{mm}$ culture dishes at the concentration of $1 \times 10^{6}$ cells $/ \mathrm{ml}$. After an initial culture for $30 \mathrm{~min}$, the medium was changed to remove freefloating cells. The isolated decidual cells were further cultured in fresh complete medium at $37{ }^{\circ} \mathrm{C}$ with $5 \% \mathrm{CO}_{2}$ before treatments.

\section{Plasmid construction and transfection}

A 1221-bp Tdo2 cDNA fragment isolated from the mouse uterus was amplified by PCR, using the following primers with EcoRv/xhoI restriction sites: 5'-GATATC (EcoRv) ATGAGTGGGTGCCCGTTTGC-3'; 5'-CTCGAG (XhoI)

Table 1 Primers for real-time PCR

\begin{tabular}{|c|c|c|c|}
\hline Genes & Primer sequences & Accession numbers & Size $(b p)$ \\
\hline Tryptophan 2,3-dioxygenase (Tdo2) & $\begin{array}{l}\text { CTGGGGGATCCTCAGGCTAT } \\
\text { TGTCACTGTACTCGGCTGTG }\end{array}$ & NM_019911 & 165 \\
\hline $\begin{array}{l}\text { Decidual/trophoblast PRL-related protein } \\
\text { (Dtprp) }\end{array}$ & $\begin{array}{l}\text { AGCCAGAAATCACTGCCACT } \\
\text { TGATCCATGCACCCATAAAA }\end{array}$ & NM_010088 & 119 \\
\hline Aryl hydrocarbon receptor $(A h r)$ & $\begin{array}{l}\text { CCGAAGCACACGCAAATCAA } \\
\text { CCCTTCCAGGGAAGTCCAAC }\end{array}$ & NM_013464 & 244 \\
\hline Cyclooxygenase 2 (Cox2) & $\begin{array}{l}\text { CATCCCCTTCCTGCGAAGTT } \\
\text { CATGGGAGTTGGGCAGTCAT }\end{array}$ & NM_011198 & 178 \\
\hline $\begin{array}{l}\text { Vascular endothelial growth factor } \\
\text { (Vegf) }\end{array}$ & $\begin{array}{l}\text { ACGTCAGAGAGCAACATCACC } \\
\text { CTGTGCTGTAGGAAGCTCATCTC }\end{array}$ & NM_001025257 & 90 \\
\hline $\begin{array}{l}\text { Glyceraldehyde-3-phosphate } \\
\text { dehydrogenase (Gapdh) }\end{array}$ & $\begin{array}{l}\text { GCCTTCCGTGTTCCTACCC } \\
\text { TGCCTGCTTCACCACCTTC }\end{array}$ & NM_008084 & 102 \\
\hline
\end{tabular}

http://joe.endocrinology-journals.org DOI: 10.1530/JOE-13-0429
๑ 2014 Society for Endocrinology Printed in Great Britain
Published by Bioscientifica Ltd 

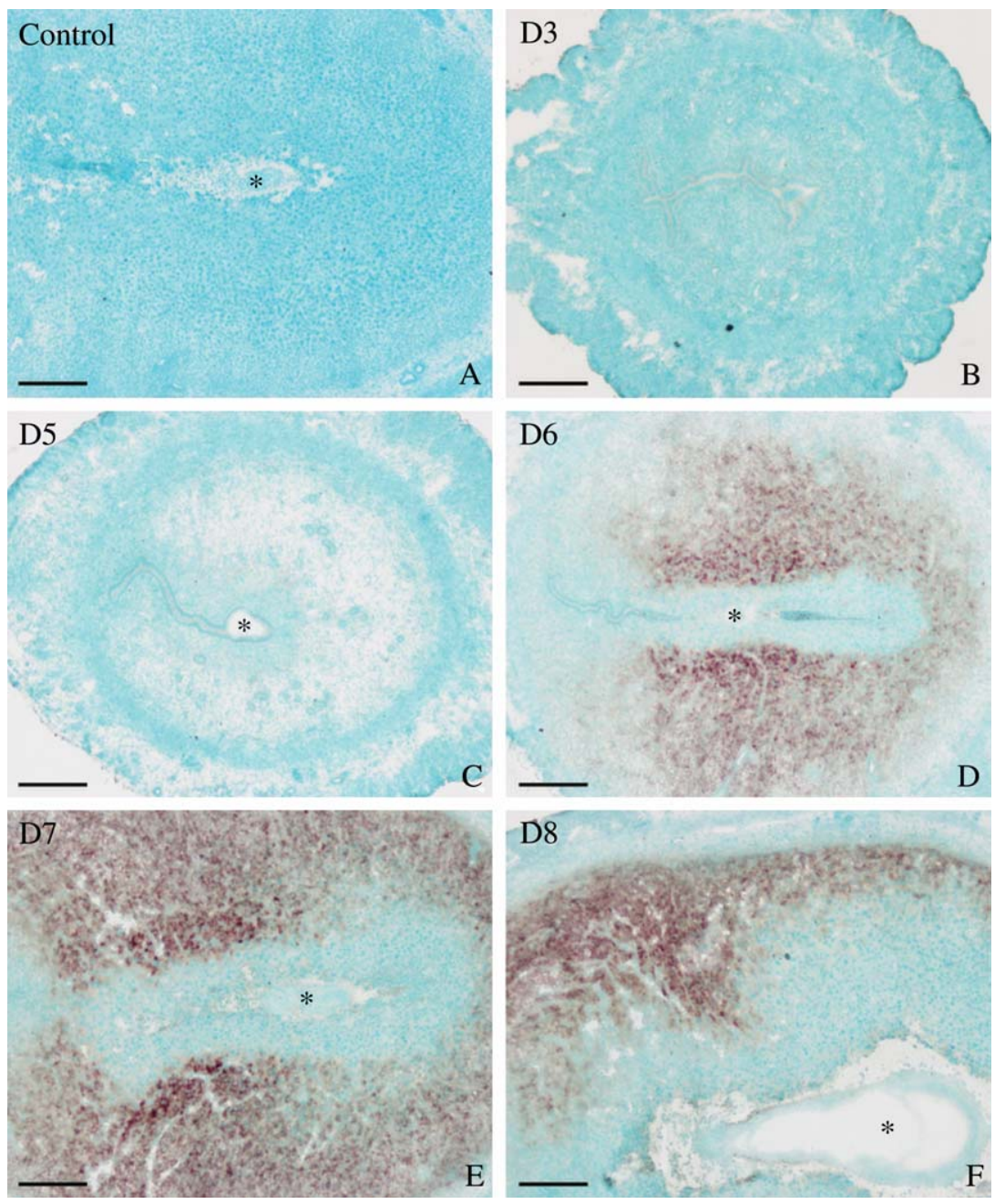

\section{Figure 1}

In situ hybridization of $T d o 2$ expression in mouse uteri during early pregnancy on days 3 (B), 5 (C), 6 (D), 7 (E), and 8 (F). No hybridization signals were seen in mouse uterus on day 7 of pregnancy when DIG-labeled Tdo2

TCAATCCGATTCATCGCTGC-3'. The amplified product was purified and cloned into pGEM-T vector. Both pGEMT-Tdo2 and pcDNA3.1 vectors were cut by EcoRv/XhoI (TaKaRa, Dalian, China) at $37^{\circ} \mathrm{C}$ for $1 \mathrm{~h}$, and then the fragment was ligated into pcDNA3.1 with T4 ligase (Promega) at $4{ }^{\circ} \mathrm{C}$ overnight to construct pcDNA-Tdo2 (pc-Tdo2). An empty pcDNA3.1 expression vector was used as a control.

Transfection of uterine stromal cells was performed according to the manufacturer's protocol for Lipofectamine 2000 (Invitrogen). After transfection with control plasmid (empty pcDNA3.1 vector) or pc-Tdo2 plasmid, stromal cells from day 4 pregnant mice were collected or induced for in vitro decidualization for $48 \mathrm{~h}$. sense probe was used to replace the antisense probe as a negative control (A). Asterisks indicate embryo. Bars $=60 \mu \mathrm{m}$.

\section{Cell proliferation}

Proliferation assays were performed using MTS reagent (Promega) according to the manufacturer's directions. Uterine stromal cells were seeded at a density of $1 \times 10^{5}$ per well in 96-well plates and cultured in the DMEM-F12 medium containing $2 \%$ heat-inactivated FBS. The cells were treated for $24 \mathrm{~h}$ with a medium containing 0.01, $0.05,0.1,0.5,1,5$, or $10 \mu \mathrm{M}$ Tdo2 inhibitor 680C91 after being induced for in vitro decidualization for $24 \mathrm{~h}$. Finally $20 \mu \mathrm{l}$ of MTS reagent was added to each well and incubated for $4 \mathrm{~h}$. The absorbance was measured at $490 \mathrm{~nm}$ using a 96-well plate reader. Simultaneously, uterine decidual cells treated with $10 \mu \mathrm{M}$ Tdo2 inhibitor 680C91 and stromal cells after transfection with $p c$-Tdo2 plasmid

Published by Bioscientifica Ltd. 


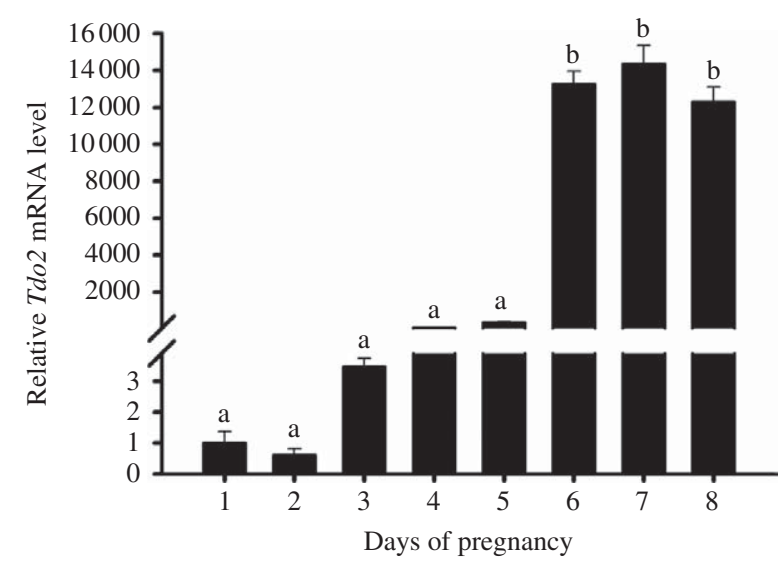

Figure 2

Real-time PCR analysis of Tdo2 expression in mouse uterus on days 1-8 during pregnancy. Data are presented as mean \pm s.E.M. Bars with different letters at the top differ significantly.

were also analyzed post addition of MTS. Every experiment was performed in triplicate.

\section{Statistical analysis}

All the experiments were independently repeated at least three times. The significance of differences was analyzed by one-way ANOVA using the SPSS Software Program (SPSS, Inc.). The differences were considered significant at $P<0.05$.

\section{Results}

\section{Tdo2 mRNA expression during early pregnancy}

In situ hybridization was used to examine the spatial distribution of Tdo2 mRNA in mouse uterus. No Tdo2 mRNA signal was detected in the uteri from days 1 to 5 of pregnancy (Fig. 1B and C). On day 6 of pregnancy, a high level of Tdo2 mRNA signal was observed in decidualized cells surrounding the implanting embryo (Fig. 1D). On day 7 , Tdo2 expression was similar to that observed on day 6 but at much higher levels and scopes (Fig. 1E). When Tdo2 antisense probe was replaced by $T d o 2$ sense probe, there was no corresponding signal in the uterus on day 7 of pregnancy (Fig. 1A). On day 8, Tdo2 mRNA was primarily localized in decidualized cells of the mesometrial region (Fig. 1F). In addition, Tdo2 mRNA was not detected in the embryos from days 5 to 8 of pregnancy by in situ hybridization (Fig. 1C, D, E and F).

To quantify Tdo 2 mRNA expression, real-time PCR was performed. Tdo2 was highly expressed in the uteri from days 6 to 8 of pregnancy, although Tdo 2 expression was detected throughout days 1-8 (Fig. 2).

\section{Tdo2 mRNA expression during pseudopregnancy}

There was no detectable Tdo2 mRNA signal in the uteri from days 1 to 5 of pseudopregnancy by in situ hybridization (Fig. 3A). However, a high level of Tdo2 expression was detected on day 5 of pseudopregnancy by real-time PCR, although Tdo2 expression was seen from days 1 to 5 (Fig. 3B).

\section{Tdo2 expression under artificial decidualization}

Tdo2 mRNA signal was strongly detected in the decidualized cell under artificial decidualization, but not found in uninjected control uterus (Fig. 3A). By real-time PCR analysis, a significantly higher level of Tdo2 expression was detected in the decidualized uterus compared with the control uterus (Fig. 3C).

\section{Tdo2 expression under in vitro decidualization}

Primary stromal cells isolated from mouse uteri on day 4 of pregnancy were treated with a combination of estrogen and progesterone to induce in vitro decidualization. The success of decidualization was confirmed by a reliable marker for decidualization, decidual/trophoblast PRLrelated protein (Dtprp) which was detected in the decidualized stromal cells after $24 \mathrm{~h}$ with significant time-dependent increases at $48 \mathrm{~h}$ and a maximum at $96 \mathrm{~h}$ (Fig. 4A). Likewise, elevated expression levels of Tdo2 were also observed in the decidualized stromal cells with a time-dependent increase (Fig. 4B).

\section{Regulatory effects of CAMP and H89 on Tdo2 expression}

Initiation of the decidual process requires elevated intracellular cAMP levels and sustained activation of the protein kinase A (PKA) pathway (Gellersen \& Brosens 2003). To examine the effects of cAMP and H89 on Tdo2 expression, we treated the uterine stromal cells with cAMP analog 8-bromoadenosine-cAMP (8-Br-cAMP, $500 \mu \mathrm{M})$ and PKA inhibitor H89 $(10 \mu \mathrm{M})$. The results showed that Tdo2 expression was gradually increased after uterine stromal cells were treated with 8-Br-cAMP and reached the highest level at $24 \mathrm{~h}$ (Fig. 5A). The 8-Br-cAMP stimulation of Tdo2 expression was also dramatically altered by the addition of the PKA inhibitor H89 (Fig. 5B).

Published by Bioscientifica Ltd 
A

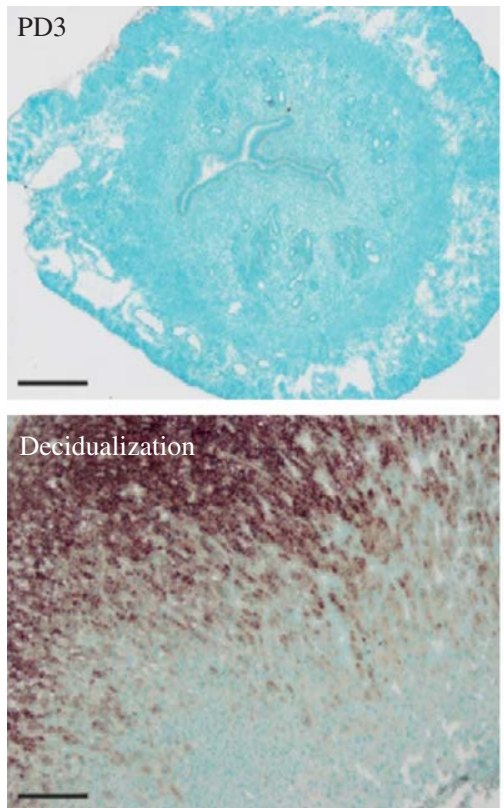

$\mathrm{B}$

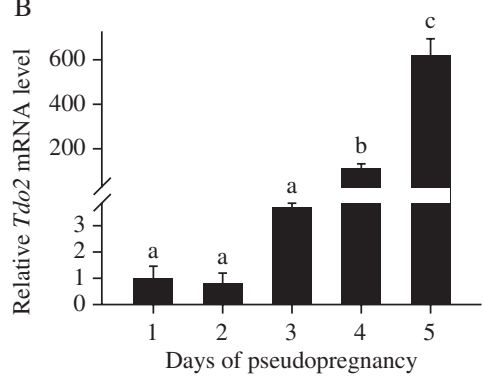

PD5
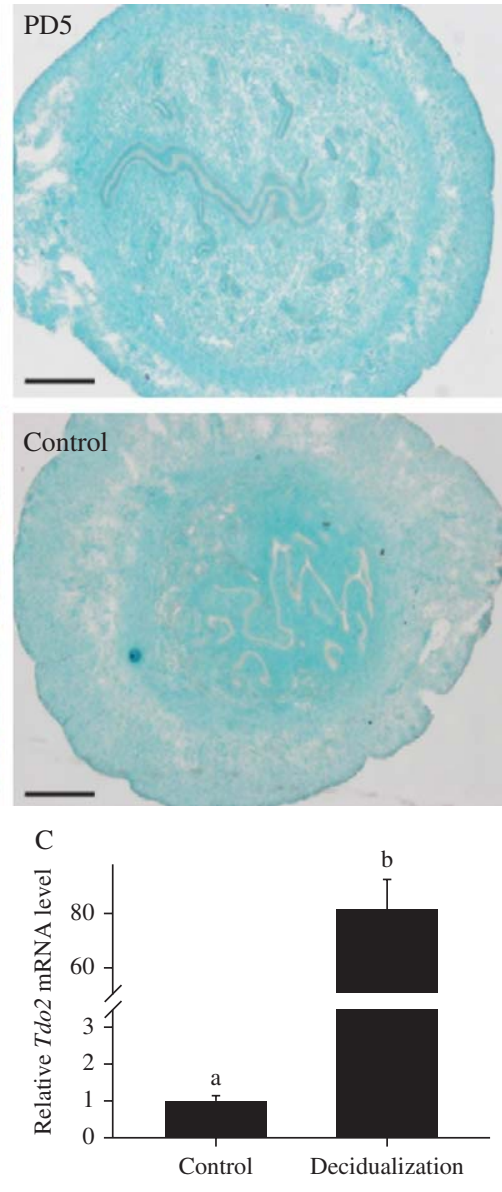

Figure 3

Tdo2 expression during pseudopregnancy and artificial decidualization. (A) In situ hybridization of Tdo2 expression in mouse uteri during pseudopregnancy on days 3 (PD3) and PD5, and after artificial decidualization. Bar $=60 \mu \mathrm{m}$. (B) Real-time PCR analysis of $T d o 2$ expression

\section{Regulatory effects of steroid hormones on Tdo2 expression}

To determine whether steroid hormones could regulate Tdo2 expression, ovariectomized mice were given a single injection of oil (control), estrogen, or progesterone, and then Tdo2 mRNA was detected in the uteri by in situ hybridization and real-time PCR. The in situ hybridization results showed that neither estrogen nor progesterone had any obvious effects on the expression of Tdo2 (data not shown). By real-time PCR analysis, Tdo2 mRNA expression was gradually enhanced in the uteri of ovariectomized mice and reached a peak at $24 \mathrm{~h}$ after injection of progesterone (Fig. 6B). However, the upregulation of progesterone was significantly blocked by pretreatment with RU486 antagonist (Fig. 6D). Likewise, injection of in mouse uterus on days 1-5 during pseudopregnancy. (C) Real-time PCR analysis of $T d o 2$ expression under artificial decidualization. Data are presented as mean \pm s.E.M. Bars with different letters at the top differ significantly.

estrogen also resulted in an increase in uterine Tdo2 mRNA level at $24 \mathrm{~h}$ (Fig. 6A). After pretreatment with ICI 182 780, Tdo2 mRNA expression significantly declined compared with that of estrogen treatment only (Fig. 6C).

In the in vitro cultured stromal cells, both estrogen and progesterone could induce Tdo2 mRNA expression at $24 \mathrm{~h}$ (Fig. 6E and F). However, the estrogen-induced stimulation of $T d o 2$ expression was blocked by estrogen receptor antagonist ICI 182780 (Fig. 6E). A similar result was also observed for RU486 treatment (Fig. 6F).

\section{Effect of Tdo2 on decidualization}

Stromal cell proliferation is the first step of decidualization. To examine the effect of Tdo2 on stromal cell proliferation, we treated stromal cells with Tdo2 inhibitor 680C91 after

Published by Bioscientifica Ltd. 

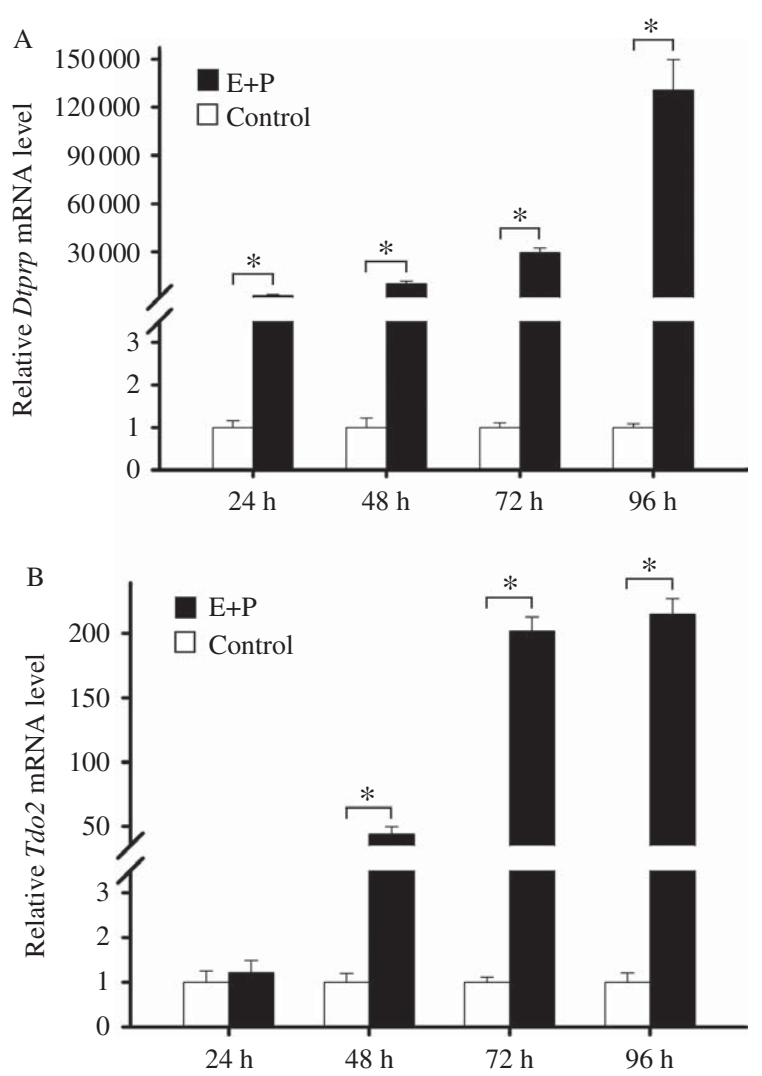

Figure 4

Real-time PCR analysis of Dtprp (A) and Tdo2 (B) expression in in vitro decidualization of uterine stromal cells. Data are presented as mean \pm s.E.M. *Statistical significance $(P<0.05) ; E$, estrogen; $P$, progesterone.

induction for in vitro decidualization for $24 \mathrm{~h}$. The results showed that proliferation activity of stromal cells was significantly decreased by 5 and $10 \mu \mathrm{M}$ Tdo2 inhibitor 680C91 (Fig. 7A). In contrast, proliferation of uterine stromal cells displayed a significant increase at $48 \mathrm{~h}$ after transfection with pc-Tdo2 plasmid (Fig. 7C). Additionally, the Tdo2 inhibitor $680 \mathrm{C} 91$ could also inhibit the proliferation activity of uterine decidual cells at $24 \mathrm{~h}$ (Fig. 7B).

To further verify the effect of Tdo2 on decidualization, we transfected uterine stromal cells with the pc-Tdo2 expression plasmid and examined the expression of Tdo2 and Dtprp by real-time PCR. The results showed that Tdo2 mRNA expression was significantly upregulated in the pc-Tdo2-transfected cells compared with the pcDNA3.1transfected cells (Fig. 8A). Meanwhile, overexpression of Tdo 2 could induce the expression of Dtprp (Fig. 8B). Under in vitro decidualization, Tdo2 and Dtprp mRNA levels were also significantly elevated by Tdo2 overexpression compared with those of controls (Fig. 8C and D). In contrast, the Tdo2 inhibitor 680C91 could inhibit the expression of Dtprp gene under in vitro decidualization and in the uterine decidual cells (Fig. 8E and F).

\section{Regulatory effects of Tdo2 on Ahr, Cox2, and Vegf expression}

In the in vitro cultured stromal cells, overexpression of Tdo 2 could result in an increase in uterine aryl hydrocarbon receptor $(A h r)$, cyclooxygenase 2 (Cox2), and vascular endothelial growth factor (Vegf) mRNA levels at $48 \mathrm{~h}$ (Fig. 9A, C and E). In contrast, the Tdo2 inhibitor 680C91 could inhibit the expression of Cox2 and Vegf genes in the uterine decidual cells (Fig. 9D and F), whereas it had hardly any effect on Ahr expression (Fig. 9B).

\section{Discussion}

In this study, we have investigated the expression and regulation of $T d o 2$ in mouse uterus during early pregnancy in order to provide insight into the physiological function of Tdo2 during decidualization. The results showed that the Tdo2 mRNA signal was strongly detected in the decidua on days $6-8$ of pregnancy using real-time PCR and in situ hybridization. This was consistent with previous results (Tatsumi et al. 2000). Likewise, increased

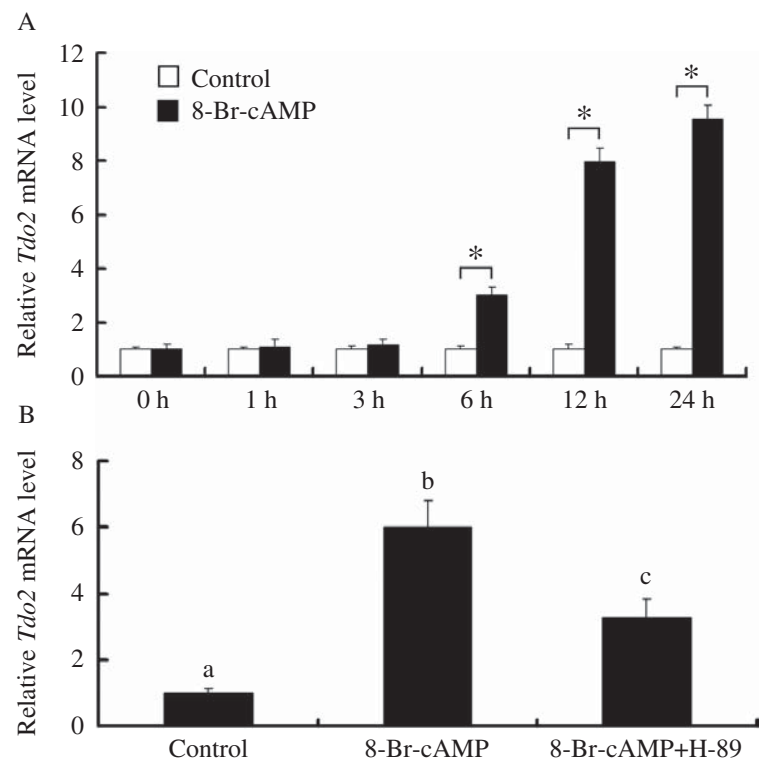

Figure 5

Effects of 8-Br-cAMP and $\mathrm{H} 89$ on $\mathrm{Tdo} 2$ expression in the uterine stromal cells. (A) Tdo2 expression in the uterine stromal cells after 8-Br-cAMP treatment. Data are presented as mean \pm S.E.M. *Statistical significance $(P<0.05)$. (B) Tdo2 expression after stromal cells were treated with 8-Br-cAMP, or both 8-Br-CAMP and H-89. Bars with different letters at the top differ significantly. 


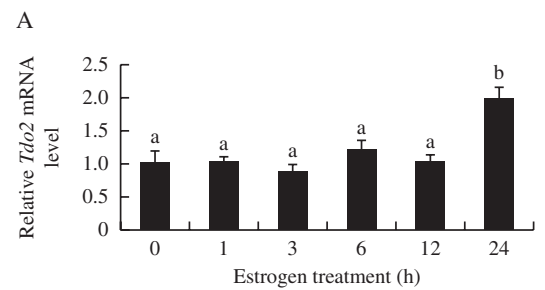

B
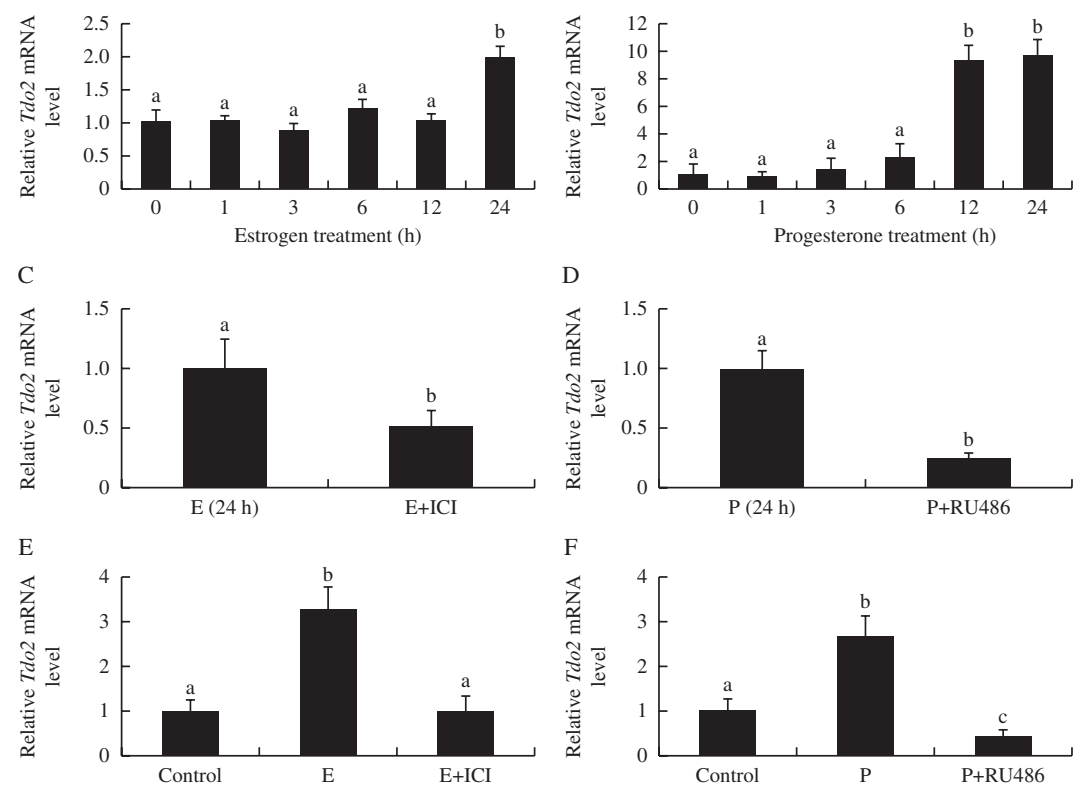

Figure 6

Hormonal regulation of Tdo2 expression. (A) Real-time PCR analysis of $T d o 2$ expression in ovariectomized mouse uterus after estrogen ( $E$ ) treatments for $0,1,3,6,12$, and $24 \mathrm{~h}$. (B) Tdo2 expression in ovariectomized mouse uterus after injection of progesterone (P). (C) Tdo2 expression in ovariectomized mouse uterus after injection of estrogen and ICI 182780. (D) Tdo2 expression in ovariectomized mouse uterus after injection of

expression of Tdo2 was confirmed by using artificial decidualization and an in vitro decidualization system. These results indicate that Tdo2 may be involved in mouse decidualization. Decidualization is a process which is characterized by uterine stromal cells proliferating and differentiating into decidual cells with polyploidy (Das 2009). This study showed that Tdo2 could regulate the proliferation of uterine stromal cells and decidual cells. Moreover, overexpression of Tdo2 could stimulate the expression of the decidual marker Dtprp in uterine stromal cells, while inhibition of Tdo2 could cause a decrease in Dtprp mRNA level in uterine stromal cells and decidual cells. These results confirm the effect of Tdo2 on decidualization. Because both inhibition and targeted disruption of Tdo2 could lead to an increase in available tryptophan and circulating serotonin levels (Salter et al. 1995, Kanai et al. 2009), Tdo2 expression in decidualized cells demonstrated that Tdo2 might increase tryptophan catabolism in the decidual zone and decrease available tryptophan for production of serotonin that could inhibit the process of decidualization (Mitchell et al. 1983), which further supports a role for Tdo2 in decidualization.

progesterone and RU486. (E) Tdo2 expression after stromal cells were treated with estrogen, or both estrogen and ICI 182 780. (F) Tdo2 expression after stromal cells were treated with progesterone, or both progesterone and RU486. Data are presented as mean \pm s.E.M. Bars with different letters at the top differ significantly.
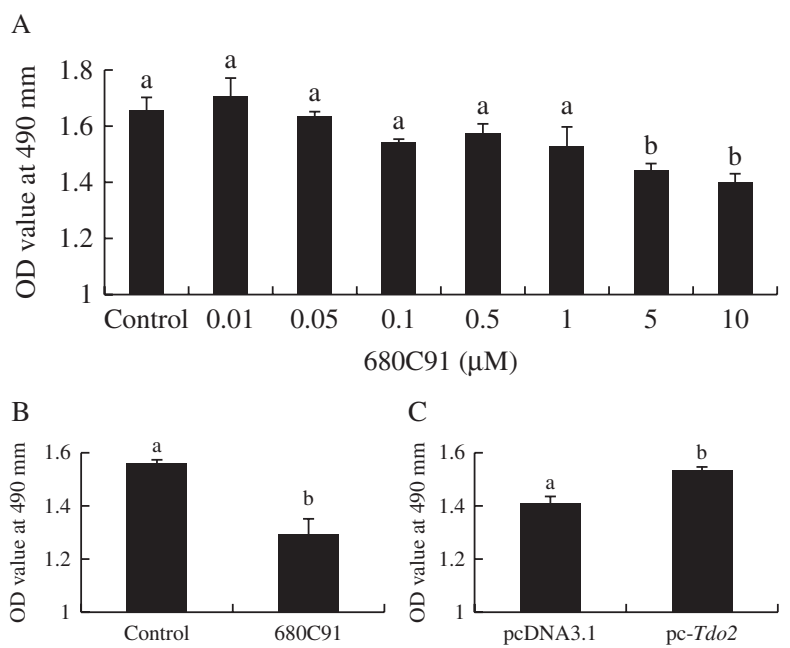

Figure 7

Effects of Tdo2 on cell proliferation. (A) Uterine stromal cells were treated with various concentration of $T d o 2$ inhibitor $680 \mathrm{C} 91$ after induction for in vitro decidualization for $24 \mathrm{~h}$. Cell proliferation was determined by MTS assay. (B) Uterine decidual cells after $10 \mu \mathrm{M}$ Tdo2 inhibitor $680 \mathrm{C} 91$ treatment were examined by MTS assay. (C) Uterine stromal cells after transfection with pc-Tdo2 plasmid were analyzed by MTS assay. Data are presented as mean \pm S.E.M. Bars with different letters at the top differ significantly.

Published by Bioscientifica Ltd. 

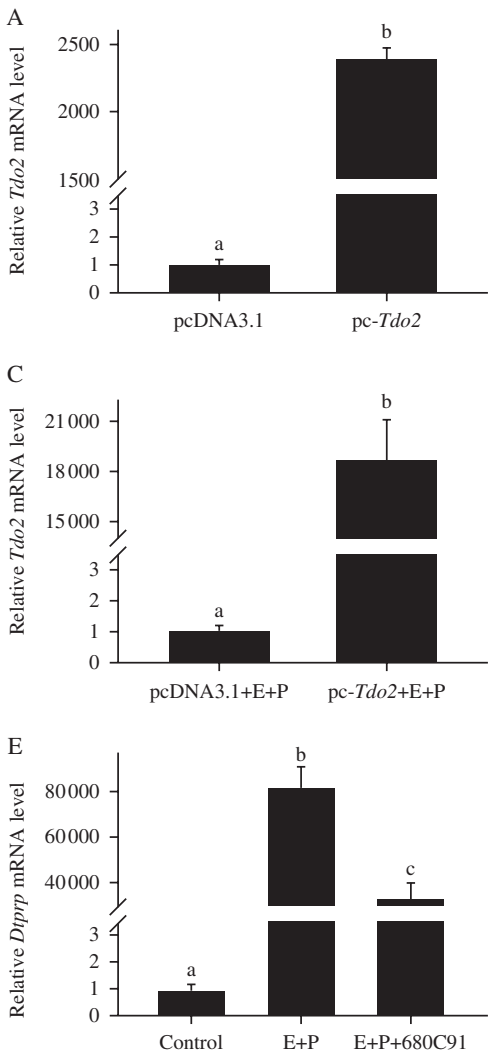

Figure 8

Effects of Tdo2 on Dtprp expression. (A) Tdo2 mRNA expression following Tdo2 overexpression. (B) Effects of Tdo2 overexpression on Dtprp mRNA expression. (C and D) Effects of Tdo2 overexpression on Tdo2 and Dtprp mRNA expression. After transfection with control plasmid (empty pcDNA3.1 vector) or Tdo2 overexpression plasmid (pc-Tdo2) for $6 \mathrm{~h}$, the stromal cells were induced for in vitro decidualization for $48 \mathrm{~h}$. (E) Effects of Tdo2 inhibitor 680C91 on Dtprp expression in the uterine stromal cells.

Tdo2 is a rate-limiting enzyme of the tryptophan degradation pathway, producing kynurenine (Thackray et al. 2008). In the glioma cell lines, kynurenine might activate the $A h r$ which is a ligand-activated transcription factor and might play a pivotal role in the physiology of reproduction, including regulation of ovarian function, establishment of an optimum environment for fertilization, and maintenance of pregnancy (Hernández-Ochoa et al. 2009, Opitz et al. 2011). This result showed that Tdo2 could modulate the expression of $A h r$ in the uterine stromal cells. Further study found that $A h r$ could induce transcription of Cox2 in breast cancer MCF7 cells (Degner et al. 2007). Cox2 is an inducible rate-limiting enzyme in the biosynthesis of prostaglandins and implicated in mouse decidualization (Lim et al. 1997, Diao et al. 2007, Zhang et al. 2013). Inhibition or deficiency of Cox2 could result in defective decidualization (Lim et al. 1997, Diao et al. 2007).
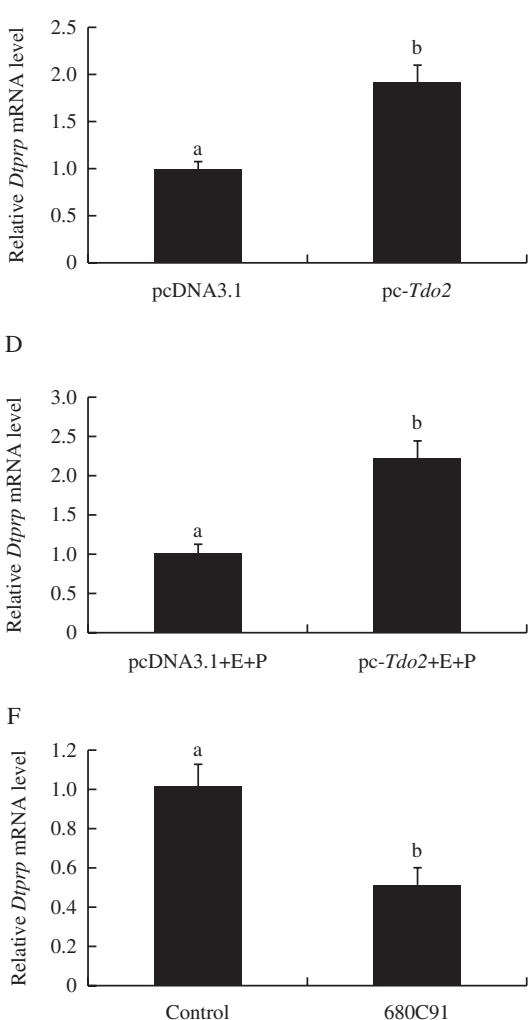

Stromal cells were treated for $48 \mathrm{~h}$ with Tdo2 inhibitor $680 \mathrm{C} 91$ after induction for in vitro decidualization for $24 \mathrm{~h}$. (F) Effects of Tdo2 inhibitor 680 C91 on Dtprp expression in the uterine decidual cells. After uterine decidual cells were treated with Tdo2 inhibitor 680C91 for $24 \mathrm{~h}$, Dtprp mRNA expression was determined by real-time PCR. Data are presented as mean \pm S.E.M. Bars with different letters at the top differ significantly.

In this study, Cox2 expression was stimulated by Tdo2 overexpression in the uterine stromal cells and downregulated by a $T d o 2$ inhibitor in the uterine decidual cells, indicating that Tdo2 might regulate mouse decidualization through influencing the expression of Cox2. Because Cox2 could promote uterine angiogenesis primarily via the Vegf system (Matsumoto et al. 2002), we examined the effect of Tdo2 on the expression of Vegf. Indeed, Tdo2 might also modulate the expression of Vegf in uterine stromal cells and decidual cells. These results indicate that Tdo2 might direct uterine angiogenesis by affecting the expression of Cox2 and Vegf during decidualization.

Decidualization of endometrial stromal cells is a prerequisite for maintenance of pregnancy, and regulated by ovarian estrogen and progesterone (Zhang et al. 2013). Ovariectomy could lead to a reduction in the Tdo2 activity in the homogenates of liver from mature rats

Published by Bioscientifica Ltd. 


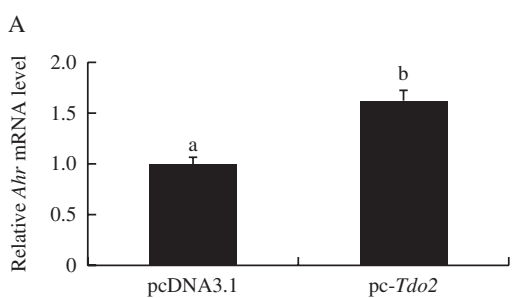

B
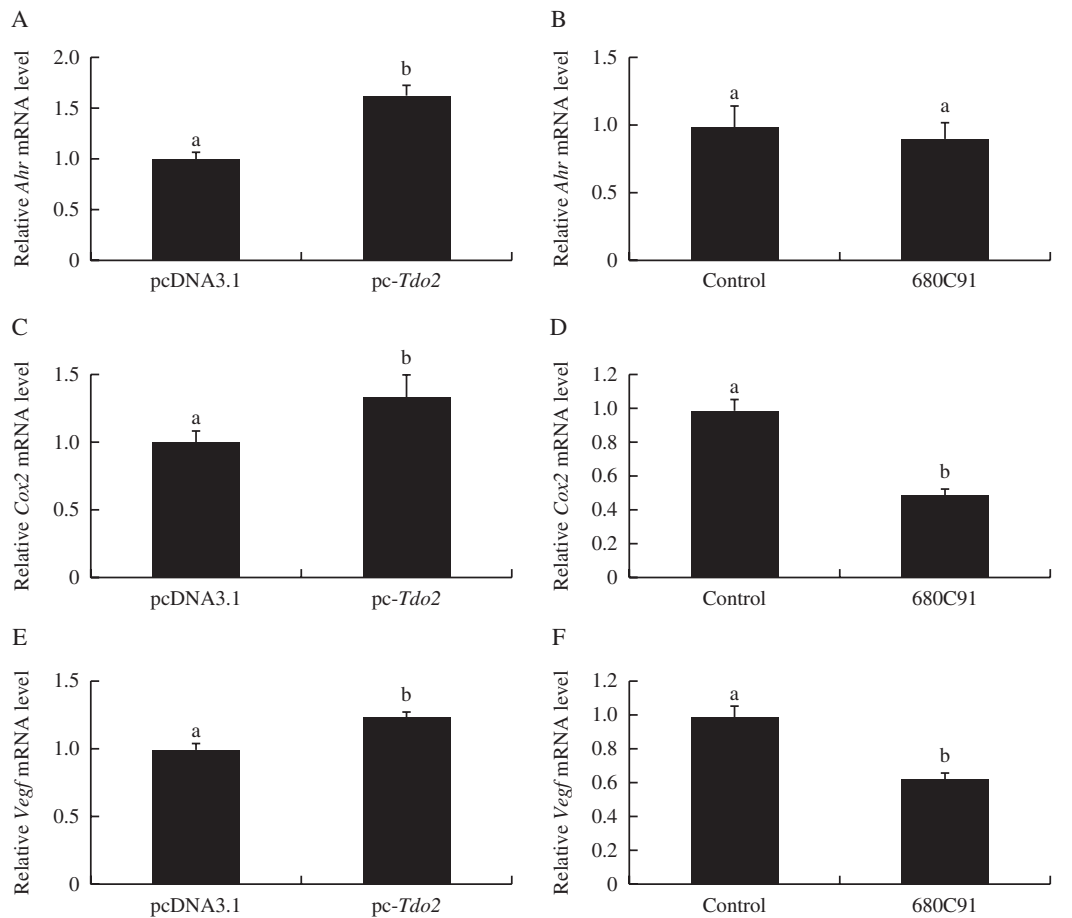

\section{Figure 9}

Regulatory effects of $T d o 2$ on $A h r$, Cox2, and Vegf expression. (A) Effects of Tdo2 overexpression on Ahr mRNA expression. After transfection with control plasmid (empty pcDNA3.1 vector) or Tdo2 overexpression plasmid (pc-Tdo2) in the stromal cells, Ahr mRNA expression was determined by real-time PCR. (B) Effects of Tdo2 inhibitor $680 \mathrm{C} 91$ on Ahr expression in the uterine decidual cells. (C) Effects of Tdo2 overexpression on Cox2 mRNA

(Bender et al. 1983, Oxenkrug 2010), indicating that ovarian hormones could regulate the expression of Tdo2. Indeed, progesterone could upregulate the expression of Tdo2 mRNA in ovariectomized mouse uterus and uterine stromal cells. Moreover, the upregulation could be antagonized by the progesterone receptor antagonist RU486, indicating its requirement for this induction. Likewise, estrogen could also induce Tdo2 expression via estrogen receptors in ovariectomized mouse uterus and uterine stromal cells. However, another study found that neither estrogen nor progesterone had any obvious effect on the induction of Tdo2 mRNA in ovariectomized mouse uterus (Tatsumi et al. 2000). The discrepancy might be attributable to differences in sensitivity between real-time PCR and northern blot. Simultaneously, cAMP might also induce the decidualization of endometrial stromal cells and stimulate the expression of decidual marker genes. Moreover, cAMP might also mediate progesterone-dependent decidualization (Brar et al. 1997). Further study found that cAMP triggered decidualization with a sustained activation of the PKA pathway that could sensitize the stromal cells to the expression. (D) Effects of Tdo2 inhibitor 680C91 on Cox2 expression in the uterine decidual cells. (E) Effects of Tdo2 overexpression on Vegf mRNA expression. (F) Effects of Tdo2 inhibitor 680C91 on Vegf expression in the uterine decidual cells. Data are presented as mean \pm s.E.M. Bars with different letters at the top differ significantly.

activity of progesterone (Gellersen \& Brosens 2003, Logan et al. 2013). This study showed that cAMP could stimulate the expression of Tdo2 in the uterine stromal cells and that the stimulation was blocked by the PKA inhibitor H89, indicating that the action of cAMP on Tdo2 expression was mediated by the PKA signaling pathway. In addition, the pattern of Tdo2 expression on days 1-5 of pseudopregnancy was similar to that on days $1-5$ of pregnancy, showing that $T d o 2$ expression was independent of the embryo. In conclusion, Tdo2 may play an important role during mouse decidualization and be regulated by estrogen, progesterone, and cAMP.

\section{Declaration of interest}

The authors declare that there is no conflict of interest that could be perceived as prejudicing the impartiality of the research reported.

\section{Funding}

This work was financially supported by Special Funds for Scientific Research on Public Causes (201303119) and National Natural Science Foundation of China (31101778 and 31372390).

Published by Bioscientifica Ltd 


\section{References}

Bender DA, Laing AE, Vale JA, Papadaki L \& Pugh M 1983 The effects of oestrogen administration on tryptophan metabolism in rats and in menopausal women receiving hormone replacement therapy. Biochemical Pharmacology 32 843-848. (doi:10.1016/0006-2952(83)90586-5)

Benson GV, Lim H, Paria BC, Satokata I, Dey SK \& Maas RL 1996 Mechanisms of reduced fertility in Hoxa-10 mutant mice: uterine homeosis and loss of maternal Hoxa-10 expression. Development 122 2687-2696.

Brar AK, Frank GR, Kessler CA, Cedars MI \& Handwerger S 1997 Progesterone-dependent decidualization of the human endometrium is mediated by cAMP. Endocrine 6 301-307. (doi:10.1007/BF02820507)

Britan A, Maffre V, Tone S \& Drevet JR 2006 Quantitative and spatial differences in the expression of tryptophan-metabolizing enzymes in mouse epididymis. Cell and Tissue Research 324 301-310. (doi:10.1007/ s00441-005-0151-7)

Das SK 2009 Cell cycle regulatory control for uterine stromal cell decidualization in implantation. Reproduction 137 889-899. (doi:10.1530/REP-08-0539)

Degner SC, Kemp MQ, Hockings JK \& Romagnolo DF 2007 Cyclooxygenase- 2 promoter activation by the aromatic hydrocarbon receptor in breast cancer mcf-7 cells: repressive effects of conjugated linoleic acid. Nutrition and Cancer 59 248-257. (doi:10.1080/ 01635580701485585)

Diao HL, Zhu H, Ma H, Tan HN, Cong J, Su RW \& Yang ZM 2007 Rat ovulation, implantation and decidualization are severely compromised by COX-2 inhibitors. Frontiers in Bioscience 12 3333-3342. (doi:10.2741/2316)

Doherty LF, Kwon HE \& Taylor HS 2011 Regulation of tryptophan 2,3-dioxygenase by HOXA10 enhances embryo viability through serotonin signaling. American Journal of Physiology. Endocrinology and Metabolism 300 E86-E93. (doi:10.1152/ajpendo.00439.2010)

Gellersen B \& Brosens J 2003 Cyclic AMP and progesterone receptor cross-talk in human endometrium: a decidualizing affair. Journal of Endocrinology 178 357-372. (doi:10.1677/joe.0.1780357)

Germeyer A, Sharkey AM, Prasadajudio M, Sherwin R, Moffett A, Bieback K, Clausmeyer S, Masters L, Popovici RM, Hess AP et al. 2009 Paracrine effects of uterine leucocytes on gene expression of human uterine stromal fibroblasts. Molecular Human Reproduction 15 39-48. (doi:10.1093/molehr/gan075)

Groebner AE, Schulke K, Schefold JC, Fusch G, Sinowatz F, Reichenbach HD, Wolf E, Meyer HH \& Ulbrich SE 2011 Immunological mechanisms to establish embryo tolerance in early bovine pregnancy. Reproduction, Fertility, and Development 23 619-632. (doi:10.1071/RD10230)

Guo B, Zhang XM, Li SJ, Tian XC, Wang ST, Li DD, Liu JX \& Yue ZP 2012 Differential expression and regulation of angiopoietin-3 in mouse uterus during preimplantation period. Journal of Experimental Zoology. Part B, Molecular and Developmental Evolution 318 316-324. (doi:10.1002/jez.b.22449)

Hernández-Ochoa I, Karman BN \& Flaws JA 2009 The role of the aryl hydrocarbon receptor in the female reproductive system. Biochemical Pharmacology 77 547-559. (doi:10.1016/j.bcp.2008.09.037)

Kanai M, Funakoshi H, Takahashi H, Hayakawa T, Mizuno S, Matsumoto K \& Nakamura T 2009 Tryptophan 2,3-dioxygenase is a key modulator of physiological neurogenesis and anxiety-related behavior in mice. Molecular Brain Research 2 8. (doi:10.1186/1756-6606-2-8)

Lim H, Paria BC, Das SK, Dinchuk JE, Langenbach R, Trzaskos JM \& Dey SK 1997 Multiple female reproductive failures in cyclooxygenase 2-deficient mice. Cell 91 197-208. (doi:10.1016/S0092-8674(00)80402-X)
Logan PC, Ponnampalam AP, Steiner M \& Mitchell MD 2013 Effect of cyclic AMP and estrogen/progesterone on the transcription of DNA methyltransferases during the decidualization of human endometrial stromal cells. Molecular Human Reproduction 19 302-312. (doi:10.1093/molehr/ gas062)

Matsumoto H, Ma WG, Daikoku T, Zhao X, Paria BC, Das SK, Trzaskos JM \& Dey SK 2002 Cyclooxygenase-2 differentially directs uterine angiogenesis during implantation in mice. Journal of Biological Chemistry 277 29260-29267. (doi:10.1074/jbc.M203996200)

Minatogawa Y, Suzuki S, Ando Y, Tone S \& Takikawa O 2003 Tryptophan pyrrole ring cleavage enzymes in placenta. Advances in Experimental Medicine and Biology 527 425-434. (doi:10.1007/ 978-1-4615-0135-0 50)

Mitchell JA, Hammer RE \& Goldman H 1983 Serotonin-induced disruption of implantation in the rat: II. Suppression of decidualization. Biology of Reproduction 29 151-156. (doi:10.1095/biolreprod29.1.151)

Munn DH, Zhou M, Attwood JT, Bondarev I, Conway SJ, Marshall B, Brown C \& Mellor AL 1998 Prevention of allogeneic fetal rejection by tryptophan catabolism. Science 281 1191-1193. (doi:10.1126/science. 281.5380.1191)

Opitz CA, Litzenburger UM, Sahm F, Ott M, Tritschler I, Trump S, Schumacher T, Jestaedt L, Schrenk D, Weller M et al. 2011 An endogenous tumour-promoting ligand of the human aryl hydrocarbon receptor. Nature 478 197-203. (doi:10.1038/nature10491)

Oxenkrug GF 2010 Tryptophan kynurenine metabolism as a common mediator of genetic and environmental impacts in major depressive disorder: the serotonin hypothesis revisited 40 years later. Israel Journal of Psychiatry and Related Sciences 47 56-63.

Saito S, Shima T, Nakashima A, Shiozaki A, Ito M \& Sasaki Y 2007 What is the role of regulatory $\mathrm{T}$ cells in the success of implantation and early pregnancy? Journal of Assisted Reproduction and Genetics 24 379-386. (doi:10.1007/s10815-007-9140-y)

Salter M, Hazelwood R, Pogson CI, Iyer R \& Madge DJ 1995 The effects of a novel and selective inhibitor of tryptophan 2,3-dioxygenase on tryptophan and serotonin metabolism in the rat. Biochemical Pharmacology 49 1435-1442. (doi:10.1016/0006-2952(95)00006-L)

Schröcksnadel K, Wirleitner B, Winkler C \& Fuchs D 2006 Monitoring tryptophan metabolism in chronic immune activation. Clinica Chimica Acta 364 82-90. (doi:10.1016/j.cca.2005.06.013)

Stone TW \& Darlington LG 2002 Endogenous kynurenines as targets for drug discovery and development. Nature Reviews. Drug Discovery 1 609-620. (doi:10.1038/nrd870)

Suzuki S, Toné S, Takikawa O, Kubo T, Kohno I \& Minatogawa Y 2001 Expression of indoleamine 2,3-dioxygenase and tryptophan 2,3-dioxygenase in early concepti. Biochemical Journal 355 425-429. (doi:10.1042/0264-6021:3550425)

Tatsumi K, Higuchi T, Fujiwara H, Nakayama T, Egawa H, Itoh K, Fujii S \& Fujita J 2000 Induction of tryptophan 2,3-dioxygenase in the mouse endometrium during implantation. Biochemical and Biophysical Research Communications 274 166-170. (doi:10.1006/bbrc.2000.3115)

Thackray SJ, Mowat CG \& Chapman SK 2008 Exploring the mechanism of tryptophan 2,3-dioxygenase. Biochemical Society Transactions 36 1120-1123. (doi:10.1042/BST0361120)

Tian XC, Wang QY, Li DD, Wang ST, Yang ZQ, Guo B \& Yue ZP 2013 Differential expression and regulation of Cryab in mouse uterus during preimplantation period. Reproduction 145 577-585. (doi:10.1530/ REP-13-0042)

Zhang S, Lin H, Kong S, Wang S, Wang H, Wang H \& Armant DR 2013 Physiological and molecular determinants of embryo implantation. Molecular Aspects of Medicine 34 939-980. (doi:10.1016/j.mam.2012. 12.011)

Received in final form 31 October 2013

Accepted 1 November 2013

Accepted Preprint published online 4 November 2013 http://joe.endocrinology-journals.org DOI: 10.1530/JOE-13-0429
(C) 2014 Society for Endocrinology Printed in Great Britain 